\title{
SPEED CONTROL OF SENSORLESS BRUSHLESS DC MOTOR BY COMPUTING BACK EMF FROM LINE VOLTAGE DIFFERENCE
}

\author{
R. Sivakami \\ Department of Electrical and Electronics Engineering, \\ Christ Institute of Technology, Puducherry, India \\ G. Sugumar \\ Department of Electrical and Electronics Engineering, \\ Christ Institute of Technology, Puducherry, India
}

\begin{abstract}
Sensorless operation of permanent magnet brushless direct current (BLDC) motor drive controls the rotating speed with different applied voltage. No phase lagging is produced which leads to increase the efficiency and minimize the torque pulsation of the BLDC motor. Initially, motor can be started by following the v/f method then allows the sensorless mode after reaching the minimum speed of 500-1000rpm. The Sensorless BLDC motors are highly used due to higher efficiency, reliability power, acoustic noise, smaller, lighter, greater dynamic response, better speed versus torque characteristics, higher speed range and longer life. Thus the source voltage spikes and switching losses are reduced. This method can be demonstrated through MATLAB stimulation and DSP TMS 320LF2407A is used in the experimental setup to get the output.
\end{abstract}

Keywords: Back Electromotive Force (EMF) Detection, Brushless Dc (BLDC) Motor, Sensorless Control, Zero-Crossing Detector (ZCD), Sensorless Brushless DC Motor, Digital Signal Processor (DSP)

Cite this Article: R. Sivakami and G. Sugumar, Speed Control of Sensorless Brushless DC Motor by Computing Back EMF from Line Voltage Difference, International Journal of Electrical Engineering \& Technology, 10(5), 2019, pp. 31-38. http://iaeme.com/Home/issue/IJEET?Volume=10\&Issue $=5$

\section{INTRODUCTION}

The Sensorless BLDC motor is widely used in applications including domestic device, automotive, aerospace, consumer, medical, automated industrial equipment and instrumentation. These motors are used in a great amount of industrial sectors because; their architecture is suitable for any safety critical applications. The Sensorless BLDC motors are 
highly used due to higher efficiency, reliability power, acoustic noise and smaller, lighter, greater dynamic response, better speed versus torque characteristics, higher speed range and longer life. It has some advantages such as elimination of motor neutral voltage, fixed phase shift circuit, low starting speed and cost effective.

The BLDC motor is electronically commutated by power switches instead of brushes. The voltage spikes are created by the residual current that is blocked when the armature current is produced by power switches. Reduction of commutation torque ripple is already achieved in the position of sensorless BLDC motor drive [1]. Analysis, design and implementation of a high performance a $\mathrm{r}$ e achieved in cost effective sensorless scheme for BLDC Motors [2]. BLDC motors, also known as Permanent Magnet Direct Current Synchronous motors, are one of motor types that have more rapidly gained popularity, mainly because of their better characteristics and performance [3]. The BLDC motor without position and speed sensors has attracted wide attention. The two typical control methods for BLDC motor are square wave control and sinusoidal current control methods [4]. In BLDC motors, only two out of three phases are excited at any time leaving the third winding floating [5]. The back emf in the floating winding can be measured to determine the switching sequence for the commutation of power switching devices in the three phase inverter [6]. The terminal voltage of the floating winding with respect to the neutral point of motor is needed to get the zero crossing time of the back emf [7]. Integration starts when zero crossing of the back emf occurs and the integration stops when the threshold set value is reached, which gives the commutation instantly [8]. Frequency independent phase shifter for sensorless control of BLDC motor, which can shift the zero-crossing point of input signal with a specified phase delay [9]. An extended Kalman filter estimator for a brushless dc motor has been developed by Jung and Ha for speed and rotor position estimation. Rotor position information is determined indirectly by sensing the back emf from one of the three motor terminal voltages of three phase motor [10]. An obstacle to applying the extended Kalman filter algorithm to rotor position estimation is the need to set the appropriate values for the covariance matrix parameters, which reflect the uncertainties in modeling and measurements [7]. The sensorless control technique based on Zero Cross Point (ZCP) of the back emf has been widely used for the low cost application [8]. Zero crossing detector (ZCD) is used to detect the ZCP of back emf and thus the pulse is generated by shifting $30^{\circ}$ from ZCP. In the ZCP method, the back emf cannot be obtained when the BLDC motor is at standstill or operating nearly zero speed [9]. Therefore, a special control is needed for smooth and reliable sensorless control operation of BLDC motors [10] Further [11] didn't discuss the details of sensorless starting of the motor. However, direct commutation instant detection technique proposed in [10] and [11] lacks this flexibility to advance the commutation instant, which is possible to implement using the back emf zero-crossing detection techniques. In [12] designed and implemented an integrated circuit for the sensorless operation of BLDC motor by sensing the motor terminal voltages. Frequency independent phase shifter [13] for sensorless control of BLDC motor, which can shift the zero-crossing point of input signal with a specified phase delay. An extended Kalman filter estimator for a brushless dc motor has been developed [14] for speed and rotor position estimation. The commutation instant increases the torque production particularly at high speed operation of BLDC motor [15].The approach to zero crossing detection were used to reliably start the BLDC machine in sensorless operation. In this work, the approach is extended to propose a simple running mode algorithm.

In this work, a simple and reliable method for the detection of back emf zero-crossings for the sensorless operation using MATLAB/SIMULINK and also hardware implementation through DSP. In hardware circuit DSP is needed to produce correct instant for pulse generation. The zero crossings of the back emf are estimated indirectly from the terminal 
voltages that are measured with respect to dc negative terminal and this method does not involve any integration. Further, since the line voltages are used, the requirement of neutral potential and the common mode noise has been eliminated.

Along with this model of BLDC motor, the dynamic behavior such that no-load, load and load transients of the motor have been studied. Simulation has been carried out to study the effectiveness of the sensorless control based on detection of zero crossing from the terminal voltages differences. Section I describes the proposed back emf zero-crossing estimation method and presents the simulation results of the proposed method. Section IIpresents hardware implementation through DSP. Section III presents the conclusion.

\section{PROPOSED ZERO-CROSSING BACK EMF ESTIMATION METHOD}

Consider a BLDC motor having three stator phase windings connected in star [8]. The rotor consists of Permanent magnets. The Brushless dc motor is driven by a three phase frequency inverter in which the devices are triggered with respect to the rotor position as shown in Fig. 1.

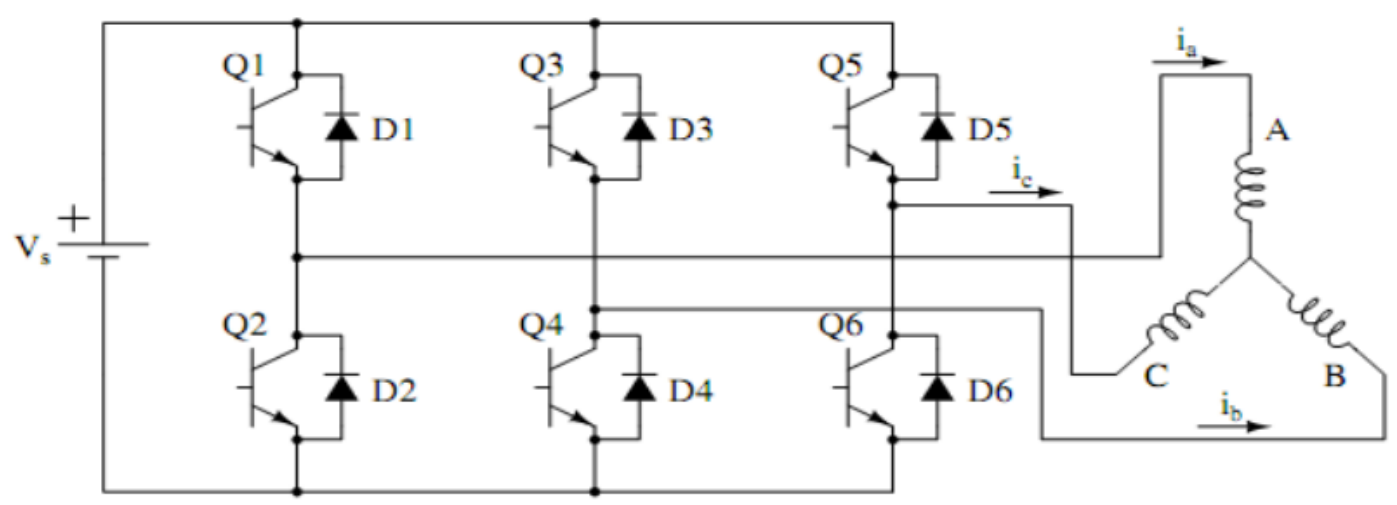

Figure 1 Equivalent circuit BLDC Motor

The phase A terminal voltage with respect to the stator, is given as

$$
v_{a n}=R_{a} I_{a}+L_{a} \frac{d_{i a}}{d t}+e_{a n}
$$

Where, $R a$ is the stator resistance, $L a$ is the phase inductance $e_{a n}$ is the back emf, and $i_{a}$ is the phase current of the "A "phase. From above equations, the line voltage $V a b$ may be determined as

$$
v_{a b}=v_{a n}-v_{b n}=R\left(i_{a}-i_{b}\right)+L \frac{d\left(i_{a}-i_{b}\right)}{d t}+e_{a n}-e_{b n}
$$

Consider the interval, when phases $\mathrm{A}$ and $\mathrm{C}$ are conducting and phase $\mathrm{B}$ is open as indicated by the shaded region. In this interval, phase $\mathrm{A}$ winding is connected to the positive terminal of dc supply, phase $\mathrm{C}$ is connected to the negative terminal of dc supply and phase $\mathrm{B}$ is open. Therefore, $i a=-i c$ and $i b=0$. It can be seen from Fig.1 (shaded region) that the back emf in phases $\mathrm{A}$ and $\mathrm{C}$ are equal and opposite. Therefore, in that interval $\mathrm{Vabbc}$ may be simplified as

$$
v_{a b b c}=v_{a b}-v_{b c}=e_{a n}-2 e_{b n}+e_{c n}=-2 e_{b n}
$$


The difference in line voltages waveform, is an inverted representation of Back EMF waveform. The Back EMF value in resistance, inductance, Back EMF (RLE) representation of the phase but not referred to ground.

\section{SIMULATION AND RESULTS}

The sensorless method is simulated in MATLAB/SIMULINK. The motor and zero crossing Detector parameters are given in Table $1 \& 2$.

Table 1 Motor Details

\begin{tabular}{|l|l|}
\hline Motor Rating & $1.1 \mathrm{hp}$ \\
\hline Rated current & $4.52 \mathrm{~A}$ \\
\hline No. of Poles & 4 \\
\hline Rated Speed & $3000 \mathrm{rpm}$ \\
& \\
\hline Supply Voltage & $320 \mathrm{~V}$ \\
\hline Rated Torque & $2.25 \mathrm{~N}-\mathrm{m}$ \\
\hline
\end{tabular}

Table 2 Zero-Crossing Detector Parameter

\begin{tabular}{|l|l|}
\hline Step down transformer & $230 / 9 \mathrm{~V}$ \\
\hline Filter Inductance & $40 \mathrm{mH}$ \\
\hline Filter capacitance & $15,0.1 \mu \mathrm{F}$ \\
\hline Resistance & $15 \mathrm{~K}, 10 \mathrm{~K}, 1.5 \mathrm{~K} \Omega$ \\
\hline Operational amplifier & $\mathrm{TL} 082$ \\
\hline
\end{tabular}

The circuit diagram of simulation of BLDC MOTOR, in sensorless mode is shown in Fig.2.From the sensed terminal voltages with respect to negative dc bus ( $V a b, V b c, V c a)$, line voltages, and subsequently their differences (Vcaab, Vabbc, Vbcca ) are determined.

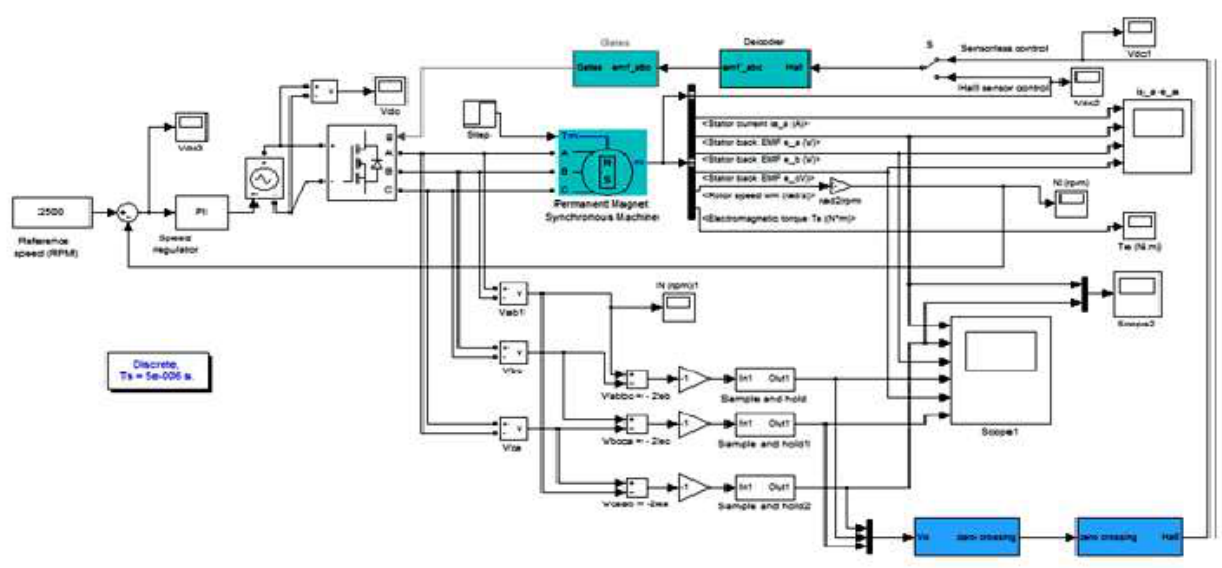

Figure 2 Simulation of BLDC motor in sensorless mode

The simulated pulse for inverter, phase currents, back emf waveforms are shown in Fig.3, 4 and 5.

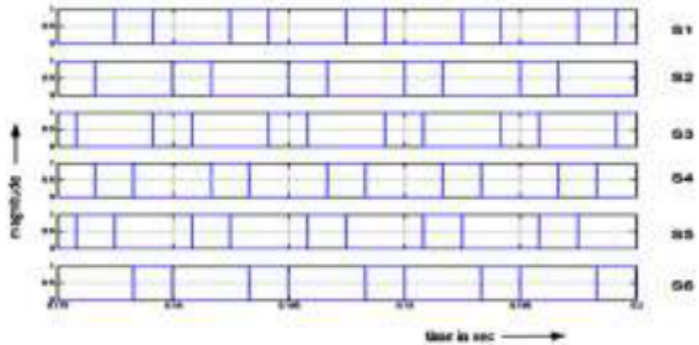

Figure 3. PWM Pulse for the Inverter

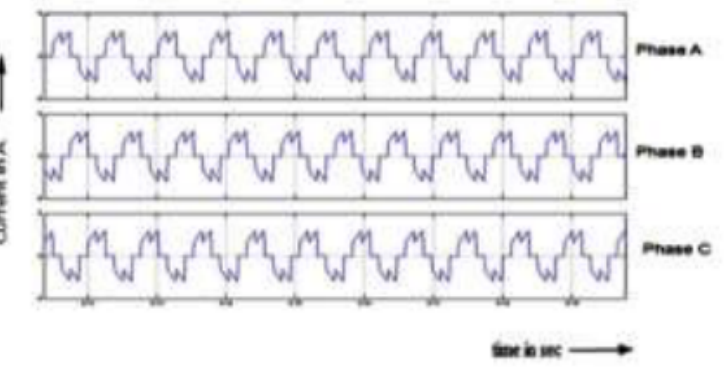

Figure 4. Phase Current waveform of SBLDCM 

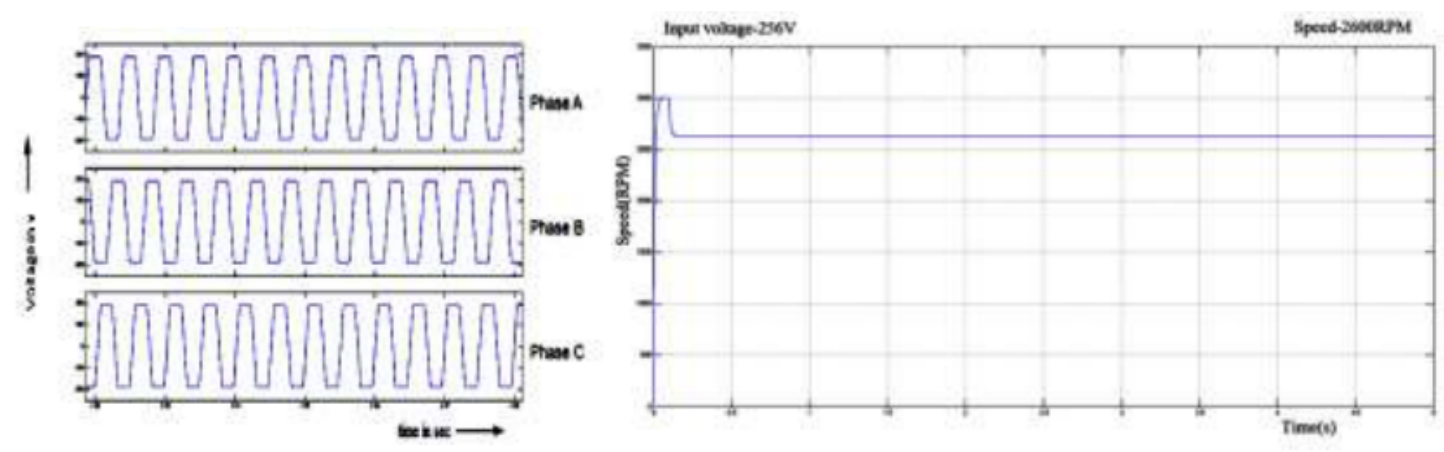

Figure 5 Back EMF Waveform of SBLDM Figure 6. Simulated speed waveform of sensorless BLDC motor

From the line voltage difference, waveforms zero crossings are detected using the zero crossing detection model. These zero crossings are decoded to corresponding signals using Zero Crossing Detector (ZCD) decoding system and are fed to Hall sensor decoder system to provide gate signal to the inverter by using two loop control method.The simulated speed waveform is shown in Fig.6

A simple technique to detect the back emf zero crossings for a BLDC motor using the line voltages is proposed. It is shown that the method provides an amplify version of the back emf. Only three motor terminal voltages need to be measured thus eliminating the need for motor neutral voltage. Running the machine in sensorless mode is then proposed, in this paper, making use of the novel zero-crossing detection algorithm. While starting relies on triggering the devices at the zero crossings detected using the proposed algorithm, continuous running is achieved by realizing the correct commutation instants $30^{\circ}$ delay from the zero crossings. The motor is found to start smoothly and run sensorless even with load and load transients. Simulation and experimental results are shown which validate the suitability of the proposed method.

\section{HARDWARE IMPLEMENTATION AND TEST RESULTS}

Terminal voltage used as the input of the zero-crossing detector is sensed from the motor terminal. Sensed terminal voltage is stepped down to $9 \mathrm{~V}$ by using step-down transformer that is used as input to the LC filter. Step down voltage contains some spikes that will be given to the voltage divider circuit for driving the voltage, and that output will be given to the voltage follower circuit for equalizing the input impedance, from that output will be given to the input of the zero-crossing detector.The Block diagram of the proposed Zero Crossing Detector is shown in Fig. 7.
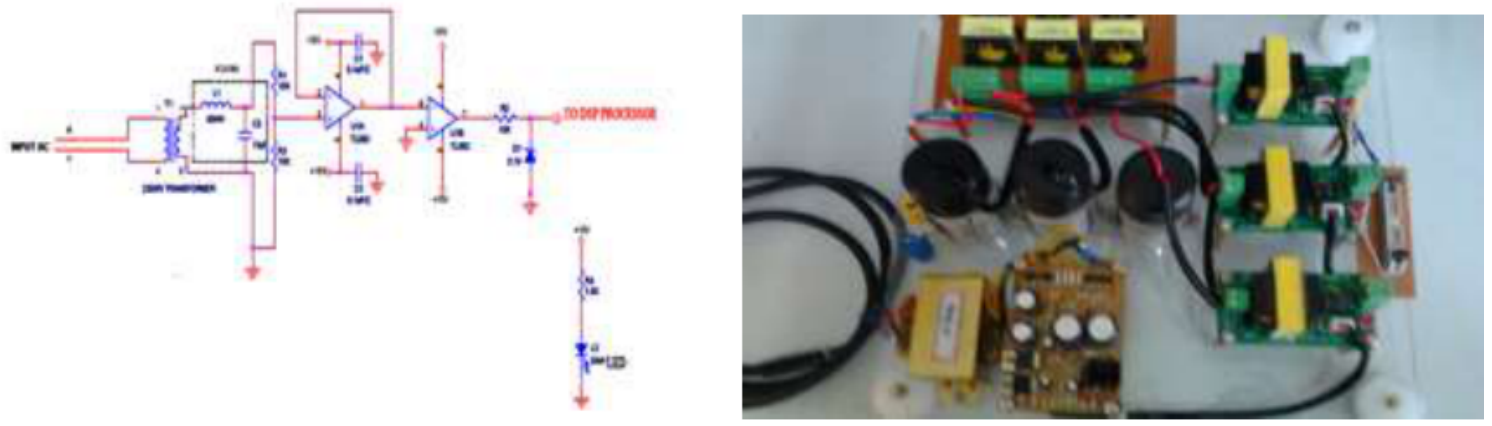

Figure 7. Block diagram of the Zero-Crossing Detector Figure 8. The experimental setup of Zero-Crossing Detector

ZCD will detect the positive zero crossing and negative zero crossing gives the low and high pulse. From that output will get the square waveform. Zener diode is used to maintain 
the output amplitude at 5.1V.Output of the ZCD will be gives to the DSP processor. The experimental setup of the proposed Zero Crossing Detector is shown in Fig.8.

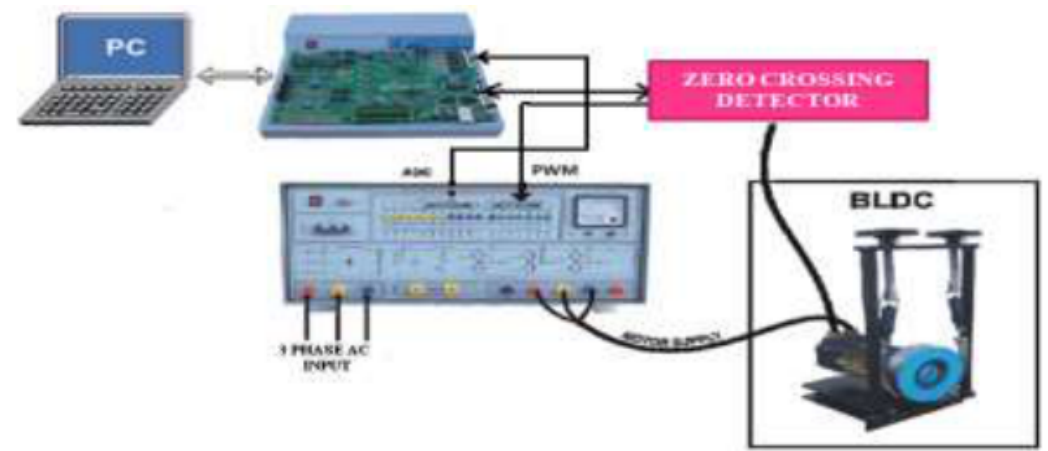

Figure 9 The experimental setup of sensorless BLDC motor

The experimental setup of the proposed sensorless BLDC motor drive is illustrated in the Fig.9. A motor with $820 \mathrm{~W}, 4600 \mathrm{rpm}$, six pole BLDC motor drive coupled to a DC generator connected to a variable resistor for loading are the parameters of the motor used in the simulation study and listed in Table I. The proposed sensorless method is implemented using TI TMS320LF2407A digital signal processor (DSP). The BLDC motor is driven by a threephase power IGBT module. The three terminal voltages of the motor are sensed and fed to the analog-to-digital converter (ADC) of the DSP through a resistive divider . In order to reduces the magnitude. The voltage spikes that appear in the sensed terminal voltage waveform due to the free-wheeling diode conduction during phase commutation are filtered out by the sample and hold method as discussed in Section III. The high-frequency switching noise due to PWM (Pulse width modulation) is filtered out by synchronizing the ADC sampling during the PWM on time.

\section{HARDWARE RESULTS}

The output of zero crossing detectors is given to DSP (TMS 320 LF 2407) and then detects the zero crossing point. From that ZCP the gate pulses are produced with the phase shift of $30^{\circ}$ and then the pulses are given to inverter. The sensorless BLDC motor current waveform for $120^{\circ}$ conduction mode at various speeds under no load, full load and transient condition, Inverter pulse and Phase current waveform. The experimental speed waveform of BLDC motor in sensorless operation at no load and on load condition is shown in Fig.10\& Fig.11

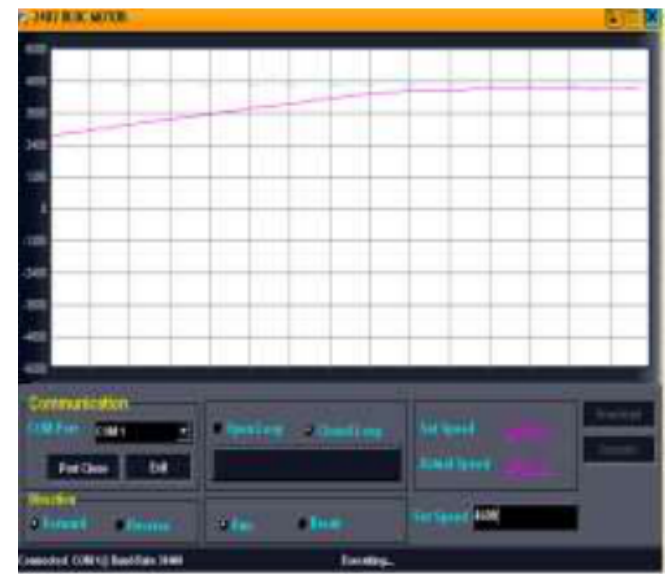

Figure 10. speed waveform from serial monitor port 2407 for BLDC 2407 for BLDC motor in sensorless operation at no load.

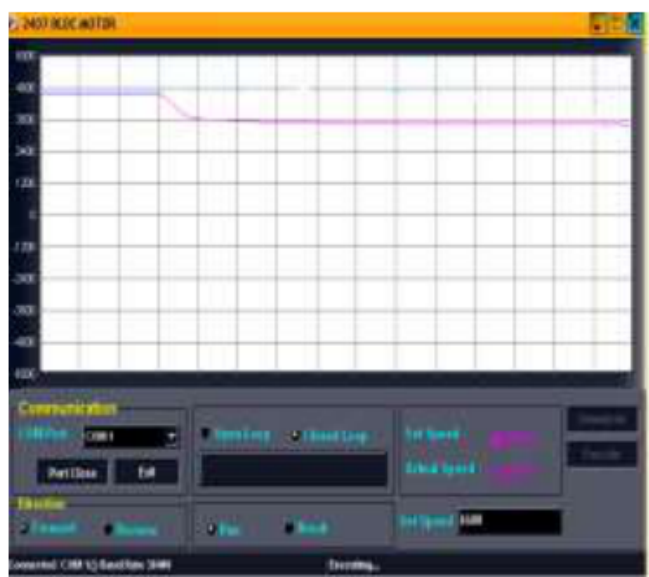

Figure 11. speed waveform from serial monitor port Motor in sensorless operation at on load. 


\section{CONCLUSION}

In this work, a simple technique to detect the back emf zero crossings from the line voltage difference by running the machine in sensorless mode is studied. It is shown that the method provides an amplified version of the back emf. Only three motor terminal voltages need to be measured and eliminate the need of motor neutral voltage. While starting the triggering devices at the zero crossing detected point by using the proposed algorithm, continuous running is achieved by realizing the correct commutation instants $30^{\circ}$ delay from the zero crossings point. The BLDC motor starts smoothly and run sensorless even with load and load transients occur due to changes in load.

\section{REFERENCES}

[1] Ang, G.H.; Park, J.H.; Chang, J.H. Position Detection and Start-Up Algorithm of a Rotor in a Sensorless BLDC Motor Utilising Inductance Variation. IEEE Proc.-Electr. Power Appl. 2002, 149, 137-142.

[2] P. P. Acarnley and J. F Watson, "Review of position-sensorless operation of brushless permanent-magnet machines," IEEE Trans. Ind. Electron., vol. 53, no. 2, pp. 352-362, Apr. 2006

[3] P. P. Carney and J. F Watson, "Review of position-sensor less operation of permanentmagnet machines," IEEE Trans. Ind. Electron., vol. 53, no. 2, pp. 352-362, Apr. 2006

[4] P. Damodharan, R. Sandeep, and K. Vasudevan, "Simple position sensor less starting method for brushless DC motor," IEEE Electro. Power Appl., vol. 2, no. 1, pp. 49-55, Jan. 2008

[5] J.X. She and S. Iwasaki, "Sensor less control of ultrahigh-speed PM brushless motor using PLL and third harmonic back EMF," IEEE Trans. Ind. Electron., vol. 53, no. 2, pp. 421-428, Apr. 2006.

[6] D.-H. Jung and I.-J. Ha, "Low-cost sensorless control of brushless DC motors using a frequency-independent phase shifter," IEEE Trans. Power Electron., vol. 15, no. 4, pp. 744-752, Jul. 2000.

[7] B. Terzic and M. Jadric, "Design and implementation of the extended Kalman filter for the speed and rotor position

[8] estimation of brushless DC motor," IEEE Trans. Ind. Electron., vol. 48, no. 6, pp. 10651073, Dec. 2001.

[9] Shao J., An improved microcontroller-based sensorless brushless DC(BLDC) motor drive for automotive applications. IEEE Trans. Ind. Appl. 42(5): 1216-1222 (2006).

[10] Lai Y.-S. Lin Y.-K., A unified approach to zero crossing point detection of back EMF for Brushless DC motor drives without current and hall sensors. IEEE Trans. Power Electron. 26(6), (2011).

[11] P. Damodharan and Krishna Vasudevan, Sensorless Brushless DC Motor Drive Based on the Zero-Crossing Detection of Back Electromotive Force (EMF) from the Line Voltage Difference, IEEE Trans on energy conversion, vol. 25, no. 3, september 2010.

[12] C.-H. Chen and M.-Y. Cheng, "New cost effective sensorless commutation method for brushless dc motors without phase shift circuit and neutral voltage, vol. 22, no. 2, pp. 644-653, Mar2007. 
[13] G.-J. Su and J. W. McKeever, "Low cost sensorless control of brushless DC motors with improved speed range vol. 19, no. 2, pp. 296-302, Mar. 2004.

[14] T.-H. Kim and M. Ehsani, "Sensorless control of BLDC motors from near-zero to high speeds," Power Electron., vol. 19, no. 6,pp. 1635-1645, Nov. 2004.

[15] R. Krishnan and R. Ghosh, "Starting Algorithm and Performance of A PM DC Brushless Motor Drive System with No Position Sensor," in Proc. IEEE PESC'89, PP.815-821, 1989.

[16] Tae-Hyung Kim and M. Ehsani, "Sensor less Control of the BLDC Motors from Near-Zero to High Speeds," IEEE Trans. Power Electron. vol. 19, No.6, pp.1635-1645, Nov. 2004. 